\title{
Neutrophil elastase downmodulates native G- CSFR expression and granulocyte-macrophage colony formation
}

\author{
Melissa G Piper ${ }^{1,2,8}$, Pam R Massullo ${ }^{3}$, Megan Loveland ${ }^{4}$, Lawrence J Druhann ${ }^{2,5}$, Tamila L Kindwall-Keller ${ }^{6}$, Jing Ai ${ }^{2,4}$, \\ Alexander Copelan ${ }^{7}$, Belinda R Avalos ${ }^{2,4,8^{*}}$
}

\begin{abstract}
Background: The granulocyte colony-stimulating factor receptor (G-CSFR) plays a critical role in maintaining homeostatic levels of circulating neutrophils (PMN). The mechanisms modulating G-CSFR surface expression to prevent chronic neutrophilia are poorly understood. Here, we report that neutrophil elastase (NE) proteolytically cleaves the G-CSFR on human PMN and blocks G-CSFR-mediated granulopoiesis in vitro.

Methods: Human peripheral blood PMN isolated from healthy donors were incubated with NE. Expression of the G-CSFR was analyzed by flow cytometry and western blot analyses. Detection of G-CSFR cleavage products from the culture supernatants was also performed. Human bone marrow mononuclear cells were also cultured in the presence or absence of $\mathrm{NE}$ to determine its effects on the proliferation of granulocyte-macrophage colony forming units (CFU-GM).

Results: Treatment of PMN with NE induced a time-dependent decrease in G-CSFR expression that correlated with its degradation and the appearance of proteolytic cleavage fragments in conditioned media. Immunoblot analysis confirmed the G-CSFR was cleaved at its amino-terminus. Treatment of progenitor cells with NE prior to culture inhibited the growth of granulocyte-macrophage colony forming units.

Conclusions: These findings indicate that in addition to transcriptional controls and ligand-induced internalization, direct proteolytic cleavage of the G-CSFR by NE also downregulates G-CSFR expression and inhibits G-CSFRmediated granulopoiesis in vitro. Our results suggest that NE negatively regulates granulopoiesis through a novel negative feedback loop.
\end{abstract}

\section{Background}

Granulocyte colony-stimulating factor (G-CSF) is the major regulator of granulopoiesis and supports the survival, proliferation, and maturation of myeloid progenitor cells along the neutrophil (PMN) lineage [1]. G-CSF also activates certain functions of mature PMN and stimulates hematopoietic stem cell mobilization [2-6]. The growth of neutrophilic granulocytes in vitro from progenitor cells committed to neutrophils and monocytes (CFU-GM) is absolutely dependent upon G-CSF and sigmoidally increases with increasing G-CSF concentrations $[2,5,7,8]$. A critical role for G-CSF in regulating

\footnotetext{
* Correspondence: belinda.avalos@osumc.edu
2The Davis Heart and Lung Research Institute, The Ohio State University,

* Correspondence: belinda.avalos@osumc.edu
2The Davis Heart and Lung Research Institute, The Ohio State University, Columbus, 43210, OH, USA
}

granulopoiesis in vivo has been demonstrated in G-CSF null mice who have chronic neutropenia and severely impaired granulopoietic responses to infection [6].

The biological activities of G-CSF are mediated by the G-CSFR receptor (G-CSFR), a transmembrane protein predominantly expressed on the surface of cells of the neutrophil lineage [7]. Like other cytokine receptors, the extracellular portion of the G-CSFR binds ligand and the cytoplasmic tail transduces intracellular signals $[3,4,7]$. Studies of mice with knock-out or knock-in mutations in their G-CSFR gene have suggested the GCSFR generates unique signals required for PMN production and marrow egress to maintain homeostatic levels of circulating PMN during basal and stress granulopoiesis [9-12]. 
G-CSFR null mice have chronic neutropenia, a uniform decrease in myeloid cells in the bone marrow, and defects in PMN activation [6,10]. Competitive repopulation assays in these mice indicate G-CSF drives nearly all of granulopoiesis under basal conditions and that GCSFR signals regulate the in vivo production and maintenance of both committed-myeloid progenitor cells and primitive multipotential progenitors [12]. Additional insights have come from mice expressing a chimeric GCSFR (GEpoR) comprised of the extracellular ligandbinding domain of the G-CSFR fused to the cytoplasmic domain of the erythropoietin receptor (EpoR) [13]. GEpoR mice retain the ability to produce PMN but have chronic neutropenia, and despite near normal bone marrow PMN levels, G-CSF treatment fails to mobilize significant numbers of PMN into the peripheral blood.

The regulated manner in which PMN are produced and released into the circulation suggests that positive regulation of granulopoiesis via G-CSF/G-CSFR interactions must be balanced by negative feedback loops $[14,15]$. However, little is known about the mechanisms downregulating G-CSFR surface expression to negatively regulate granulopoiesis. An in vivo role for neutrophil granule enzymes in both modulating PMN and stem cell mobilization and in downregulating G-CSFR surface expression on PMN was previously suggested by Jilma [16]. Subsequent studies by Levesque et al identified neutrophil elastase (NE) as a neutrophil granule enzyme that promotes stem cell mobilization by cleaving chemokines and chemokine receptors $[17,18]$, such as stem cell derived factor-1 (SDF-1) and its corresponding receptor, CXCR4 [19].

Recent studies by our laboratory and others indicate that NE also degrades G-CSF and inhibits G-CSF-stimulated proliferative responses in vitro [20,21]. The paradigm of both ligand and receptor cleavage provided by SDF-1 and CXCR4 prompted us to investigate whether NE also cleaves the G-CSFR to modulate its expression and signaling and whether it might be the putative granule enzyme in PMN reported by Jilma that decreases GCSFR surface expression [16]. Here, we show that NE proteolytically cleaves the G-CSFR to downregulate its expression on PMN and that it also inhibits G-CSFRmediated granulopoiesis in vitro. These results suggest a novel role for $\mathrm{NE}$ as a negative regulator of granulopoiesis.

\section{Materials and methods}

\section{Reagents and cell culture}

Recombinant human G-CSF was generously provided by Amgen (Thousand Oaks, CA). Other cytokines were purchased from R\&D Systems (Minneapolis, MN). Purified human NE was from Elastin Products Company, Inc. (Owensville, MO). Cathepsin G (CG) and azurocidin (AZ) were from Athens Research \& Technology (Athens, GA). Phenylmethylsulfonyl fluoride (PMSF) and protease inhibitors were from Sigma-Aldrich Corp. (St. Louis, MO). Anti-G-CSFR antibodies recognizing the extracellular region of the human G-CSFR were obtained from BD Biosciences (Palo Alto, CA). Streptavidin-Cy5 was from Invitrogen (Carlsbad, CA) and biotinylated anti-streptavidin antibody from Vector Laboratories (Burlingame, CA). The polyclonal antibody recognizing the distal tail of the murine and human GCSFR was obtained from Santa Cruz Inc (Santa Cruz, CA). Fetal bovine serum (FBS), RPMI media, and serum-free StemPro-34 media were from Invitrogen. Ba/ F3 and COS-7 cells transfected with the full-length human G-CSFR cDNA, which have previously been described, were grown in RPMI media containing $10 \%$ FBS [22,23]. For culture of Ba/F3 cells, 10\% WEHI conditioned media was also added as a source of interleukin-3 (IL-3).

\section{Flow cytometric analyses}

PMN (97\% purity) were isolated from peripheral blood of healthy human donors following appropriate informed consent using Ficoll-Hypaque $(\mathrm{d}=1.077)$ and sedimentation in 3\% dextran sulfate. Contaminating red cells were removed by lysis in an ammonium chloride solution (BD Biosciences). PMN $\left(1 \times 10^{7}\right.$ cells $\left./ \mathrm{ml}\right)$ were incubated at $37^{\circ} \mathrm{C}$ with or without $0-150 \mu \mathrm{g} / \mathrm{ml} \mathrm{NE}, \mathrm{AZ}$, or CG for varying times. Duplicate samples to which $10 \%$ serum or $1 \mathrm{mM}$ PMSF was added during enzyme incubations were also included. Reactions were stopped by the addition of ice cold 10\% FBS. G-CSFR expression on PMN was analyzed following fixation in $1 \%$ paraformaldehyde using immunofluorescence staining and a BD FACSCalibur Cytometer equipped with Cell Quest software (BD Biosciences) as previously described [21]. Detection of proteolytic cleavage fragments of the GCSFR

$\mathrm{PMN}$ and stably transfected $\mathrm{Ba} / \mathrm{F} 3$ cells expressing the G-CSFR $\left(1 \times 10^{7}\right.$ cells $\left./ \mathrm{ml}\right)$ were incubated with $150 \mu \mathrm{g} /$ $\mathrm{ml} \mathrm{NE}$ in $\mathrm{PBS}$ at $37^{\circ} \mathrm{C}$ for $0-120$ minutes. Reactions were quenched by addition of $10 \%$ FBS and $1 \mathrm{mM}$ PMSF. Samples were centrifuged and the supernatants containing the conditioned media collected. To detect G-CSFR cleavage fragments, conditioned media and whole cell lysates from the identical time points were analyzed by immunoblot analysis. Cell pellets were lysed as previously described [21], the samples $(0.1 \mathrm{mg}$ protein) loaded onto $10 \%$ polyacrylamide gels, transferred to nitrocellulose membranes, and immunoblotted.

\section{Colony assays}

Bone marrow was aspirated from the posterior superior iliac crest of healthy donors following appropriate informed consent. The bone marrow mononuclear cell fraction (BMMNC) was isolated using Ficoll-Hypaque. 
BMMNC were sequentially washed in RPMI 1640 containing $2 \mathrm{mM}$ glutamine and 20\% FBS followed by RPMI 1640 supplemented with 10\% FBS and a final wash in StemPro-34 media. BMMNC $\left(1 \times 10^{4}\right)$ were aliquoted into two fractions. One set was directly plated in StemPro-34 containing 1\% methylcellulose (Stem Cell Technologies, Vancouver, BC, Canada), 1\% BSA, 0.1 $\mathrm{mM} \beta$-mercaptoethanol (2-ME), $2 \mathrm{mM}$ L-glutamine, 10 $\mu \mathrm{g} / \mathrm{ml}$ insulin, $200 \mu \mathrm{g} / \mathrm{ml}$ human iron-saturated transferrin, recombinant human insulin $(10 \mu \mathrm{g} / \mathrm{ml})$, G-CSF $(20$ $\mathrm{ng} / \mathrm{ml})$, stem cell factor $(50 \mathrm{ng} / \mathrm{ml})$, GM-CSF $(20 \mathrm{ng} /$ $\mathrm{ml})$, IL-3 (20 ng/ml), IL-6 (20 ng/ml), and Epo (3 units/ $\mathrm{ml})$. The second set of BMMNC was pre-incubated with $0-2 \mu \mathrm{g} / \mathrm{ml} \mathrm{NE}$ at $37^{\circ} \mathrm{C}$ for $90 \mathrm{~min}$ and washed to remove $\mathrm{NE}$ prior to plating in StemPro-34 media containing growth factors. The plated cells were incubated at $37^{\circ} \mathrm{C}$ for 14 days in a $5 \% \mathrm{CO}_{2}$ humidified incubator and colony forming units (CFU)-GM enumerated using an Olympus CK2 inverted microscope equipped with a MagnaFire Digital Camera (Olympus America, Melville, NY).

\section{Results}

\section{NE decreases G-CSFR surface expression on PMN}

We initially investigated whether treatment of freshly isolated PMN with NE altered surface expression of the endogenous G-CSFR. G-CSFR surface expression on PMN from healthy donors was analyzed before and after treatment of the cells with NE using flow cytometry $(\mathrm{n}=5)$. As shown in Figure $1 \mathrm{~A}$, a time-dependent decrease in G-CSFR surface expression with near complete loss at $2 \mathrm{~h}$ was observed following treatment of PMN with NE.

To determine whether the decrease in G-CSFR surface expression in response to NE was enzymaticallymediated, $10 \%$ serum or $1 \mathrm{mM}$ PMSF were included during the incubations. These concentrations of serum and PMSF have previously been shown to be sufficient to inhibit the enzymatic activity of $\mathrm{NE}[17,18,21]$. As shown in Figure 1B, inclusion of $10 \%$ serum during incubation of PMN with NE markedly diminished the reduction in G-CSFR numbers observed in response to NE. Serum inhibited by $50 \%$ the reduction in G-CSFR surface expression observed after treatment of PMN with NE (Figure 1B). Similar results were obtained when PMN were treated with NE for shorter time periods and when PMSF was substituted for serum (data not shown). The diminished effect of NE on G-CSFR expression when serum or PMSF was added suggested the effect of NE was enzymatically mediated. We also examined the effect of other azurophilic granule proteases (CG and AZ) on G-CSFR expression over the same concentration range as NE using PMN from the same donors, and observed that only NE significantly decreased G-CSFR surface expression (data not shown).

\section{NE degrades the G-CSFR protein on PMN}

To investigate whether the decrease in G-CSFR numbers on PMN observed in response to NE was due to enzymatic degradation of the G-CSFR, we examined the GCSFR protein in whole cell lysates. As shown in Figure $2 \mathrm{~A}$, a single band of $\mathrm{M}_{\mathrm{r}} \sim 150 \mathrm{kDa}$ corresponding to the molecular weight of the fully-processed human G-CSFR protein expressed at the cell surface was detected in immunoblots of whole cell lysates from untreated PMN using an antibody recognizing the FNIII domains in the extracellular region of the G-CSFR. Notably, when PMN were treated with NE, this band became undetectable by $30 \mathrm{~min}$, and remained undetectable after $2 \mathrm{~h}$. When $10 \%$ serum and $1 \mathrm{mM}$ PMSF were included during the incubations with $\mathrm{NE}$, the $\sim 150 \mathrm{kDa}$ band did not disappear and could still be detected at $2 \mathrm{~h}$ (Figure 2A, last lane), similar to PMN that were not treated with $\mathrm{NE}$.

In order to determine whether the inability to detect the $\sim 150 \mathrm{kDa}$ receptor band on NE-treated PMN was due to a loss of the antibody recognition site as a result of enzymatic degradation, the blot in Figure 2A was stripped and re-blotted with an antibody recognizing the cytoplasmic tail of the G-CSFR. Immunoblot analysis of whole cell lysates from untreated PMN using this antibody yielded multiple bands, including the $150 \mathrm{kDa}$ mature G-CSFR protein and a faint $\sim 130 \mathrm{kDa}$ band, two prominent bands in the $80-110 \mathrm{kDa}$ range, and two faint lower molecular weight bands (Figure 2B). When PMN were treated with NE, the $150 \mathrm{kDa}$ band could no longer be detected at $30 \mathrm{~min}$ and remained undetectable throughout the duration of the $2 \mathrm{~h}$ incubation. The intensity of the lower molecular weight bands increased as the incubation time with NE increased and appeared to correlate with the disappearance of the $150 \mathrm{kDa}$ band corresponding to the mature G-CSFR protein. In addition, this antibody detected a new $\sim 50 \mathrm{kDa}$ band in PMN treated with NE which could not be detected at any time point examined in untreated PMN. The new band was detected within $30 \mathrm{~min}$ and the intensity of this band increased with longer incubation periods over the $2 \mathrm{~h}$ time period examined. The presence of 10\% FBS completely inhibited the appearance of the new band and disappearance of the mature $150 \mathrm{kDa}$ receptor species (Figure 2B, last lane). These findings are consistent with proteolytic degradation of the G-CSFR by NE. Furthermore, the inability to detect the mature form of the G-CSFR protein on NE-treated PMN with an antibody recognizing the extracellular region of the G-CSFR and the ability to detect a new $50 \mathrm{kDa}$ band in PMN following treatment with NE solely with an antibody recognizing the cytoplasmic tail of the G-CSFR support 
A.

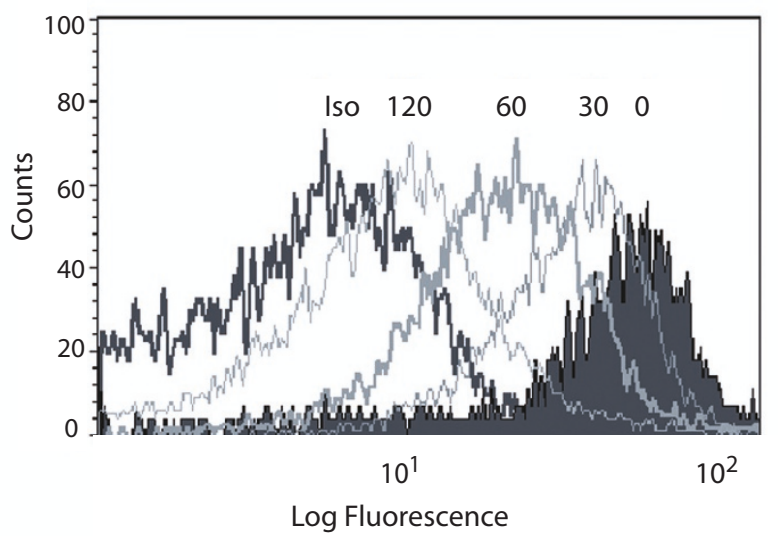

B.

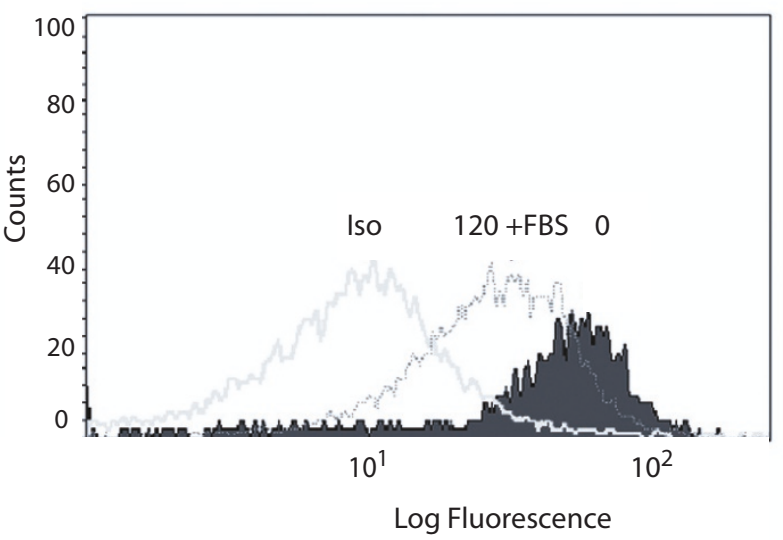

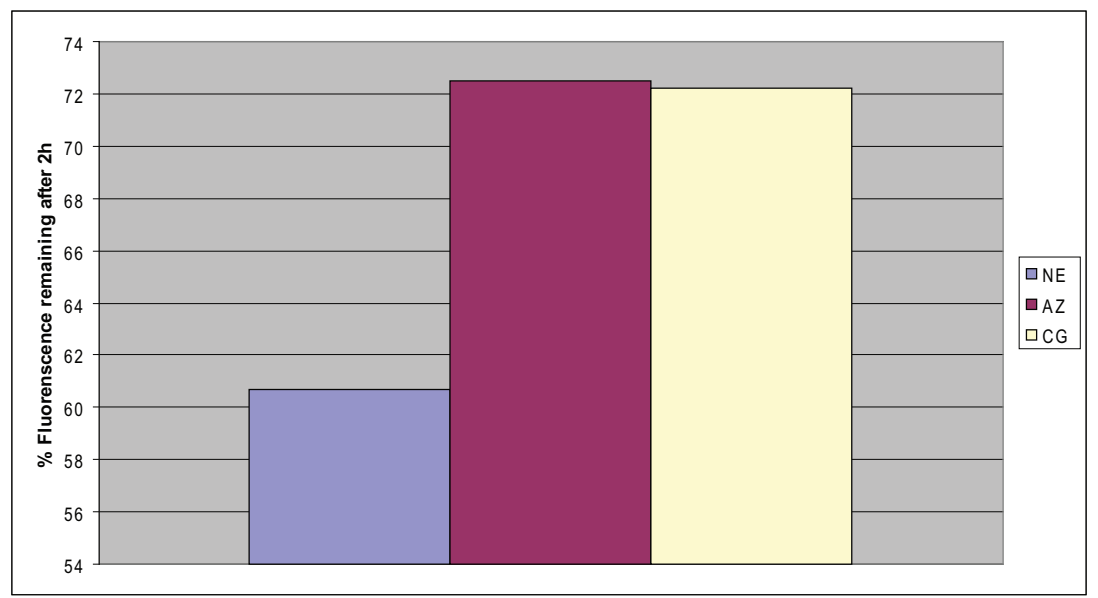

Figure 1 Neutrophil elastase (NE) decreases G-CSFR expression on human PMN. Peripheral blood neutrophils (PMN) from healthy donors ( $97 \%$ purity) were incubated $\left(1 \times 10^{7}\right.$ cells $\left./ \mathrm{ml}\right)$ with $150 \mu \mathrm{g} / \mathrm{ml} \mathrm{NE}$ at $37^{\circ} \mathrm{C}$ for the indicated times. G-CSFR surface expression was analyzed by flow cytometry as described using a biotinylated anti-G-CSFR antibody recognizing FNIII domains in the extracellular region of the G-CSFR (BD PharMingen) and a BD FACSCalibur Cytometer. A representative experiment from five independent experiments using neutrophils from five different donors is shown. (A) Effect of NE treatment for the indicated times on G-CSFR expression on PMN. Cells incubated with an isotypematched control antibody (Iso) are shown as a negative control. (B) Effect of inclusion of $10 \%$ FBS (+) during incubation of PMN with NE. (C) PMN were treated with $150 \mu \mathrm{g} / \mathrm{ml}$ of NE, azurocdin (AZ), or cathepsin G (CG) for $2 \mathrm{~h}$, then the G-CSFR was analyzed by flow cytometry. Shown is percent of fluorescence compared to maximum fluorescence at time 0 .

a mechanism whereby the G-CSFR is degraded by NE via proteolytic cleavage at a site within the extracellular portion of the G-CSFR.

\section{Detection of G-CSFR cleavage fragments in conditioned media}

We next analyzed conditioned media from untreated and NE-treated PMN for the presence of G-CSFR cleavage fragments to obtain confirmatory evidence that NE proteolytically cleaves the G-CSFR. Proteolysis within the membrane-exposed portion of the G-CSFR is predicted to result in the generation of cleaved fragments of the extracellular portion of the G-CSFR that are released into the conditioned media and detected as lower molecular weight bands that should only be apparent after NE treatment. As shown in Figure $3 \mathrm{~A}$, immunoblot analysis of the conditioned media collected from the same PMN from which whole cell lysates were examined in Figure 2 using the antibody recognizing the extracellular portion of the G-CSFR detected the presence of multiple lower molecular weight bands of $M_{r}<50 \mathrm{kDa}$ following treatment of PMN with NE. Although a prominent non-specific 


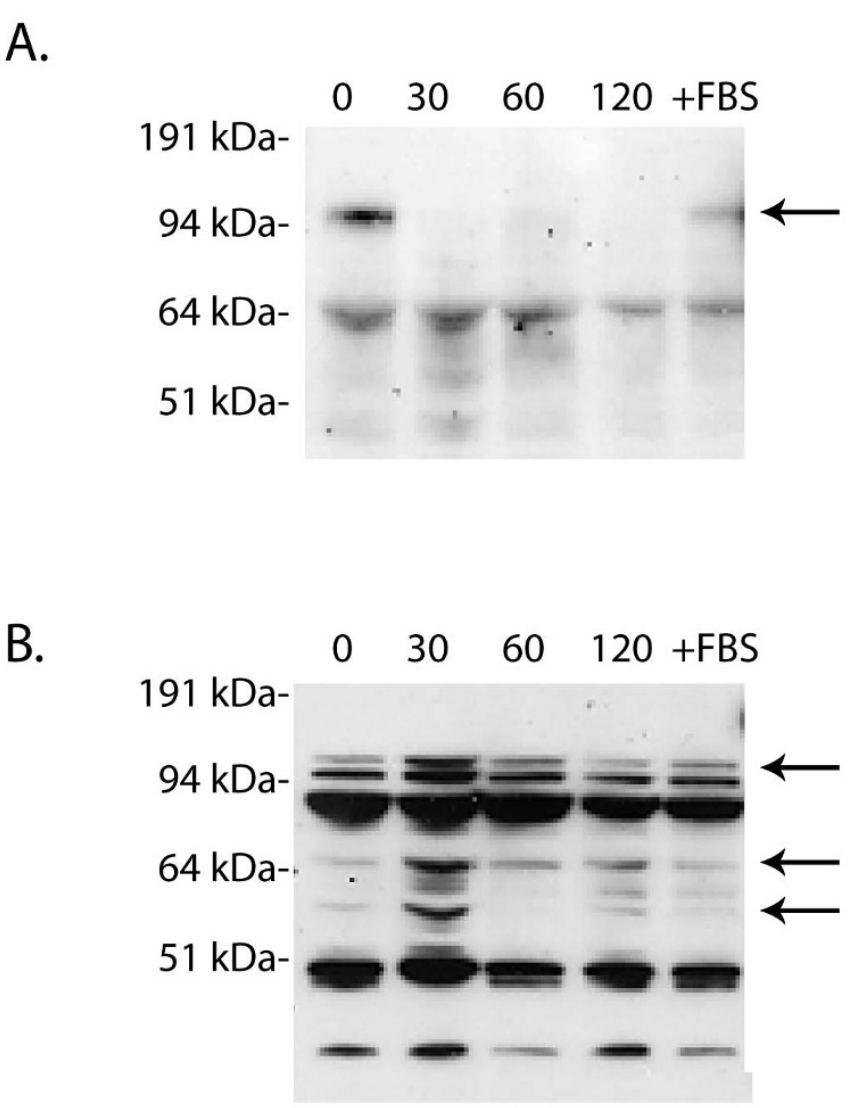

Figure 2 NE proteolytically cleaves the G-CSFR on PMN. PMN were treated with $150 \mu \mathrm{g} / \mathrm{ml}$ NE for the indicated times, the reactions quenched by addition of 10\% FBS and $1 \mathrm{mM}$ PMSF, and the cells lysed. Samples were resolved on 10\% polyacrylamide gels, transferred to nitrocellulose, and the membranes immunoblotted with $(\mathbf{A})$ the monoclonal antibody LMM741 recognizing FNIII domains in the extracellular portion of the G-CSFR (BD PharMingen). The arrow indicates the full length G-CSFR. (B) The blot in (A) was stripped then reblotted with rabbit polyclonal antibody recognizing the C-terminus of the G-CSFR (Santa Cruz). +FBS denotes lysates from PMN treated with NE for 120 min in the presence of $10 \%$ FBS. The arrows indicate the full length G-CSFR and resultant C-terminus generated by NE cleavage. A representative blot from three independent experiments $(n=3)$ is shown.

band of $\mathrm{M}_{\mathrm{r}} \sim 50-55 \mathrm{kDa}$ was seen at all time points in the conditioned media both before and after NE-treatment, immunoreactive bands of $\mathrm{M}_{\mathrm{r}}<50 \mathrm{kDa}$ could only be detected in media harvested from PMN that were treated with NE. Since the extracellular domain of the G-CSFR is predicted to have a $M_{r} \sim 60 \mathrm{kDa}$, detection of bands smaller than this only after treatment of PMN with NE supports a mechanism involving cleavage of the G-CSFR in its extracellular region. As expected, immunoblot analysis of whole cell lysates from untreated COS-7 cells transfected with the fulllength G-CSFR cDNA (Figure 3A, last lane) and of untreated PMN (Figure 2A) using the same antibody yielded a $150 \mathrm{kDa}$ band consistent with the mature membrane-anchored G-CSFR protein [23,24]. The appearance of the multiple lower molecular weight GCSFR species in conditioned media from NE-treated PMN (Figure 3A) correlated with the time course observed for degradation of the membrane-anchored G-CSFR by NE (Figure 2B). Proteolytic cleavage fragments of the G-CSFR in the conditioned media of NEtreated PMN were apparent within $60 \mathrm{~min}$, at a time when degraded forms of the G-CSFR protein could also be detected in whole cell lysates from the same PMN samples treated with NE.

Since we previously showed that in stably transfected $\mathrm{Ba} / \mathrm{F} 3$ cells the ectopically expressed G-CSFR is cleaved by $\mathrm{NE}$ [21], we also examined conditioned media from these cells for the presence of cleavage fragments of the G-CSFR. As shown in Figure 3B, treatment of Ba/F3 transfectants with NE resulted in the appearance of multiple lower molecular weight G-CSFR cleavage fragments in the conditioned media. Bands of $\mathrm{M}_{\mathrm{r}}<50 \mathrm{kDa}$ were detectable in the conditioned media by $30 \mathrm{~min}$, a time slightly earlier than their appearance in conditioned media from NE-treated PMN. 
A. PMN

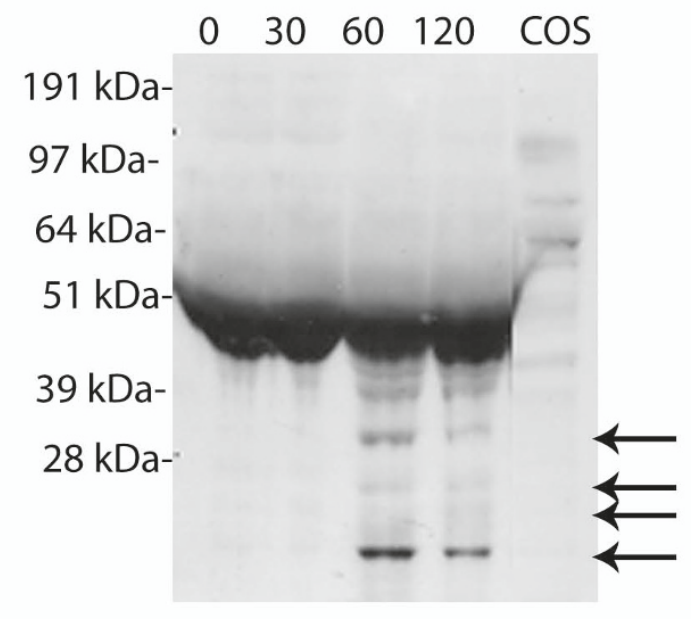

B. $\mathrm{Ba} / \mathrm{F} 3$

\section{$0 \quad 30 \quad 60 \quad 120 \quad \operatorname{COS}$}

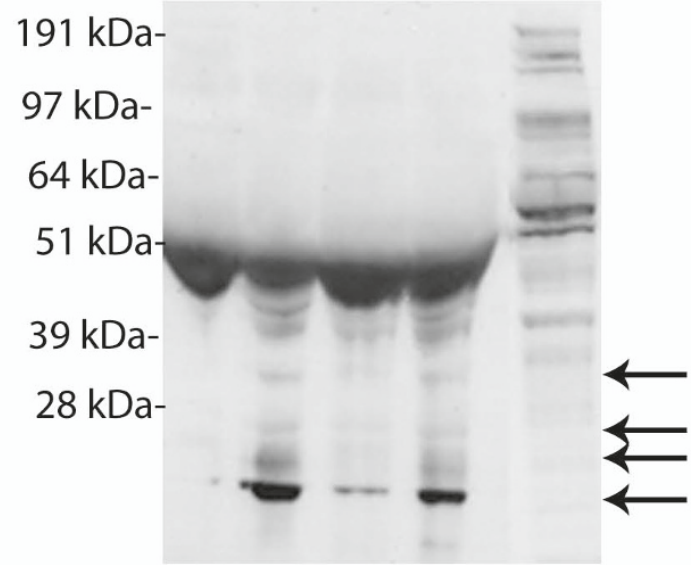

Figure 3 Detection of G-CSFR cleavage fragments in conditioned media from NE-treated cells. (A) PMN and (B) Ba/F3 cells transfected with the full-length G-CSFR CDNA were treated $\left(1 \times 10^{7}\right.$ cells) with $150 \mu \mathrm{g} / \mathrm{ml} \mathrm{NE}$ for the indicated times. Reactions were stopped by the addition of 10\% FBS and $1 \mathrm{mM}$ PMSF, the samples centrifuged, and the supernatants containing the conditioned media collected and immunoblotted with an antibody recognizing the FNIII domains in the extracellular region of the G-CSFR. Arrows indicate the extracellular GCSFR fragments generated by NE. A representative blot from three independent experiments $(n=3)$ is shown.

\section{NE inhibits G-CSFR-mediated CFU-GM growth}

Since the growth of CFU-GM in vitro has been shown to be absolutely dependent upon G-CSF, which transduces signals through the G-CSFR $[7,15]$, we investigated the effects of treatment of myeloid progenitor cells with NE on the signaling function of the G-CSFR. For these studies, the effect of NE on the growth of myeloid progenitor cells purified from the mononuclear cell fraction of bone marrow (BMMNC) from healthy human donors was examined $(n=4)$. Pre-treatment of BMMNC with NE prior to their culture in methylcellulose supplemented with G-CSF and other growth factors reduced CFU-GM growth by as much as 75\% (Figure 4). The inhibitory effect of NE on CFU-GM growth was also observed to be dose-dependent (data not shown).

\section{Discussion}

A remarkable feature of granulopoiesis is the regulated production and release of PMN to maintain homeostatic levels in the circulation during basal granulopoiesis and to rapidly increase numbers during environmental stress [15]. G-CSF is the major cytokine regulating granulopoiesis $[3,6,7]$, and its regulatory capacity depends upon its ability to bind to the G-CSFR. Thus, both G-CSF 


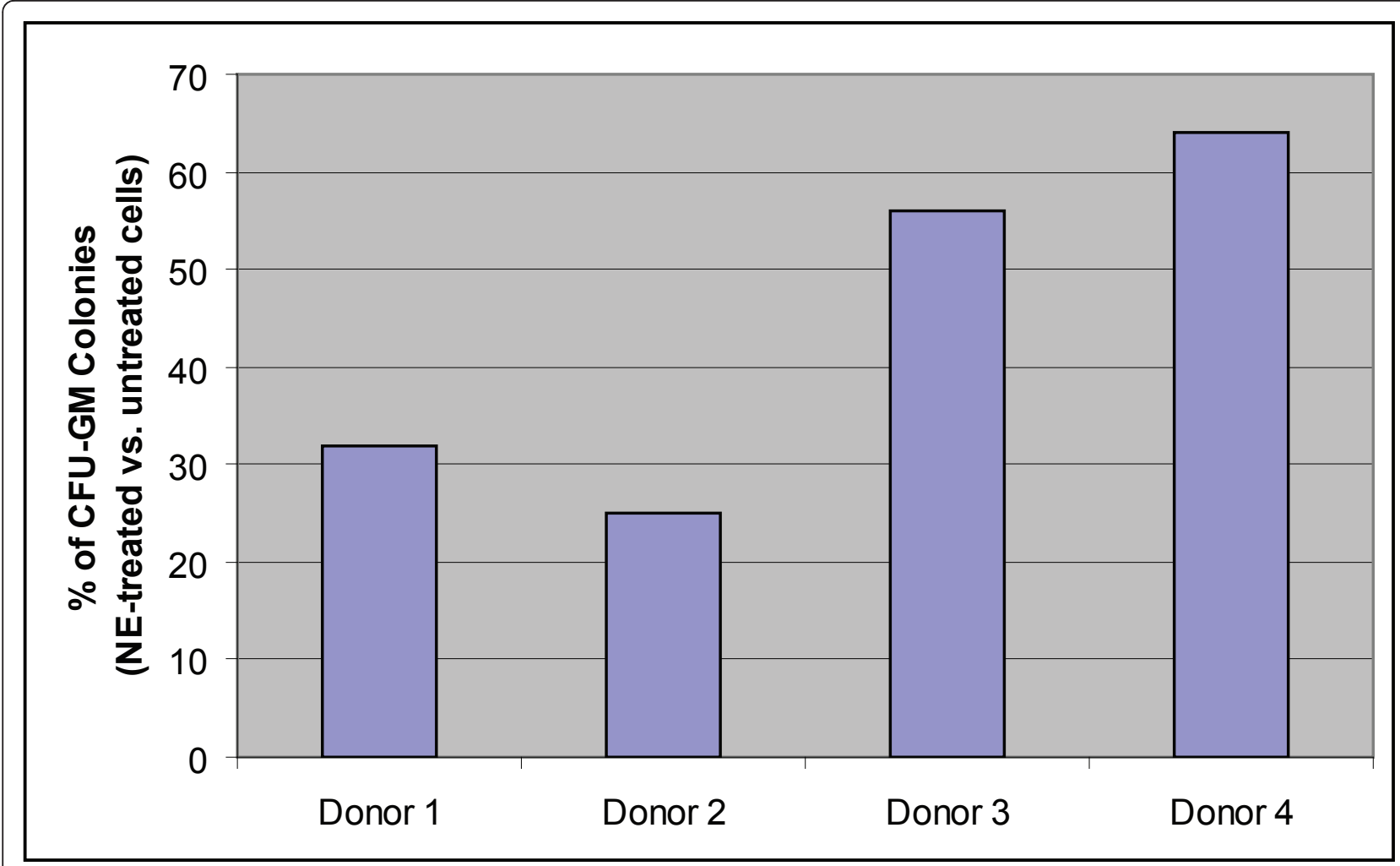

Figure 4 Pretreatment of bone marrow-derived myeloid progenitors with NE inhibits granulocyte colony formation. Bone marrow mononuclear cells (BMMNC) isolated from four healthy donors were left untreated or treated with $1 \mu \mathrm{g} / \mathrm{ml} \mathrm{NE}$ for 90 min at $37^{\circ} \mathrm{C}$. The cells were then washed, resuspended in StemPro-34 serum-free media, and plated $\left(1 \times 10^{4}\right.$ cells $)$ in serum-free Methocult containing $1 \%$ methylcellulose, G-CSF (20 ng/ml), and a cocktail of recombinant growth factors as described in the Materials and Methods. CFU-GM were enumerated after 14 days. Data are represented as the percent of CFU-GM colonies arising from NE-treated cells compared to untreated cells.

concentration and G-CSFR numbers modulate myeloid cell responsiveness and, hence, PMN numbers. The physiologic processes that regulate G-CSF levels have been well-characterized [7], but little is currently known about the mechanisms modulating G-CSFR surface expression.

Ligand-binding has been shown to trigger endocytosis and internalization of most growth factor receptors, which are then either recycled back to the cell surface or degraded intracellularly [3,24]. Ligand-induced internalization decreases the number of surface receptors and thereby serves to attenuate growth factor-induced signals [25-27]. In the case of the G-CSFR, ligand binding has been shown to modulate G-CSFR surface expression in vitro $[23,28]$. Following ligand binding, the G-CSFR on immature myeloid cells, U937 cells, and PMN is rapidly internalized and degraded [28]. More than $70 \%$ of specifically bound G-CSF is internalized after 5 min. Treatment of PMN with GM-CSF, TNF, LPS, fMLP, TPA, or C5a also downregulates G-CSFR numbers, while only TPA significantly reduces G-CSFR numbers on immature cells. There is no evidence the G-CSFR is recycled back to the cell surface.
Studies of naturally-occurring G-CSFR deletion mutants isolated from patients with severe congenital neutropenia $(\mathrm{SCN})$ transforming to acute myelogenous leukemia (AML) have provided evidence for the importance of downregulation of G-CSFR expression [29,30]. A critical cytoplasmic domain that mediates G-CSFR internalization and degradation has been shown to be deleted in cells from these patients, which exhibit enhanced growth and survival signals to G-CSF $[21,23,31,32]$. G-CSFR surface expression is prolonged and G-CSF-mediated activation of Stat 5 and Akt are sustained in these cells, indicating that receptor downregulation plays a critical role in extinction of G-CSFR signals.

There is also evidence that the G-CSFR on PMN is downregulated in vivo in response to G-CSF. Jilma et al showed that a single injection of G-CSF decreased GCSFR numbers on PMN in humans by $~ 75 \%$ [16]. These effects were noted as early as 6 min, peaked at $90 \mathrm{~min}$, and did not return to pre-treatment levels for 2 days. Notably, PMN numbers were transiently decreased and plasma levels of the neutrophil granule enzyme gelatinase b (also known as matrix metalloproteinase-9 
or MMP-9) were increased 10-fold after G-CSF administration, implying a role for gelatinase $b$ in both decreasing G-CSFR levels and PMN numbers. In related studies of the in vivo effects of lipopolysaccharide (LPS) infusion on G-CSFR expression, a significant negative correlation between PMN activation and G-CSFR expression was found [33]. The effects were reported to be independent of LPS-induced increases in G-CSF levels in vivo, suggesting that PMN activation and G-CSFR expression are tightly co-regulated.

In the current paper, we have identified an alternative mechanism for modulating G-CSFR expression on PMN involving the primary granule enzyme NE. Our data provide the first evidence that NE cleaves the endogenously expressed G-CSFR on PMN and inhibits G-CSFRmediated granulopoiesis in vitro. Treatment of PMN with NE induced a time-dependent reduction in GCSFR surface expression and the appearance of G-CSFR cleavage fragments in conditioned media from treated PMN. Both serum and PMSF could prevent degradation of the G-CSFR, suggesting NE degrades the G-CSFR by enzymatic cleavage. The time-course for the appearance of G-CSFR cleavage fragments in conditioned media from NE-treated PMN correlated well with the decrease observed in G-CSFR surface expression on treated PMN as detected by flow cytometry. We also show that NE abrogates proliferative signals generated by the G-CSFR in myeloid progenitor cells, as indicated by the decreased number of CFU-GM arising from NE-treated marrow progenitor cells. Our data demonstrate that NE cleaves the G-CSFR at a site within its extracellular portion, within which lies the ligand-binding site for GCSF. Notably, proteolytic cleavage of the G-CSFR within this region is predicted to modify the binding site for GCSF and thereby affect the sensitivity of cells to G-CSF, consistent with our data.

We [21] and others [20] have previously reported that NE also cleaves G-CSF and antagonizes its in vitro activity. However, unlike El-Ouriaghli et al who could not demonstrate an effect of NE on the G-CSFR [20], we reported that NE could also cleave the G-CSFR on transfected $\mathrm{Ba} / \mathrm{F} 3$ cells [21]. It is possible that El-Ouriaghli's group failed to observe an effect on the G-CSFR due to the significantly longer period of culture (up to seven days) in NE-containing media they used before analyzing G-CSFR expression or because of the lower $\mathrm{pH}$ (5.5 vs.7.2) of their reconstituted NE.

NE has been reported to cleave multiple substrates in addition to G-CSF and the G-CSFR including SDF-1, CXCR4, VCAM-1, CD14, CD23, and complement receptor 1 (CR1) [17-19,34-37]. For many cytokine and chemokine receptors that are cleaved by NE, the extracellular ligand binding region is the site of cleavage [17-19,36,38]. Our findings with NE and the G-CSFR suggest a similar role for NE in regulating both cytokine and its respective receptor levels as reported for SDF-1 and CXCR4 [19]. Inactivation of SDF-1/CXCR4 interactions by NE was shown to induce hematopoietic stem cell mobilization. In G-CSF-induced stem cell mobilization, NE levels increase in vivo in the plasma and bone marrow microenvironment where PMN accumulate $[17,36,39]$.

More recently, NE was reported to downregulate expression of c-KIT (CD117), the receptor for SCF [18]. Decreased c-KIT expression and increased NE levels were demonstrated in the marrows of mice receiving GCSF for stem cell mobilization. Similar to our findings with the G-CSFR, a $2 \mathrm{~h}$ incubation with NE was required to induce a $50 \%$ reduction in c-KIT surface expression.

During G-CSF-induced stem cell mobilization, plasma levels of NE dramatically increase reaching levels of approximately $1 \mathrm{mg} / \mathrm{ml}$. Within individual azurophilic granules from activated PMN, concentrations of $\mathrm{NE}$ in excess of $5 \mathrm{mM}(150 \mathrm{mg} / \mathrm{ml})$ have been measured. Thus, the concentrations of NE $(0-150 \mu \mathrm{g} / \mathrm{ml})$ and serum (a source of alpha-1 anti-trypsin) used in our experiments are well within the ranges reported in vivo [40-44].

The functional significance of our findings in vivo remains speculative, as we did not directly examine this. However, NE-induced downregulation of G-CSFR expression in vivo could promote cellular egress or inhibit further expansion of the myeloid compartment. A possible scenario is that during stem cell mobilization, release of $\mathrm{NE}$ from accumulating PMN in the bone marrow functions to inhibit granulopoiesis by degrading the G-CSFR and thereby preventing progressive and uncontrolled neutrophilia.

Our findings may have particular relevance to understanding the pathogenesis of SCN. In the majority of patients with this disease, mutations in the ELA2 gene encoding NE have been identified, some of which result in aberrant targeting of NE to the plasma membrane [45]. It is possible that such NE mutants induce aberrant and/or accelerated cleavage of the G-CSFR in some cases of SCN.

\section{Conclusions}

Our findings add the G-CSFR to the growing list of hematopoietic cytokine/chemokine receptors regulated by NE, and suggest a novel pathway for regulating GCSFR levels at the cell surface in addition to transcriptional controls and ligand-induced internalization. Cleavage of both G-CSF and the G-CSFR could provide an additional mechanism for fine-tuning PMN numbers. Future studies in humans to examine G-CSFR levels on cells in the blood and marrow before, during, and after 
stem cell mobilization, and during periods of environmental stress such as infection, may help to clarify the in vivo relevance of NE-induced cleavage of the G-CSFR.

\section{Abbreviations}

G-CSF: Granulocyte colony-stimulating factor; G-CSFR: granulocyte colonystimulating factor receptor; NE: neutrophil elastase; CG: cathepsin G; AZ: azurocidin; BMMNC: bone marrow mononuclear cell fraction; CFU-GM: colony forming units-granulocyte macrophage; IL: interleukin.

\section{Acknowledgements}

This work was supported by research grants from NCI (CA82859) and NIDDK (DK068639).

\section{Author details}

${ }^{1}$ Division of Pulmonary, Allergy, Critical Care, and Sleep Medicine, The Ohio State University, Columbus, OH, 43210, USA. ${ }^{2}$ The Davis Heart and Lung Research Institute, The Ohio State University, Columbus, 43210, OH, USA. ${ }^{3}$ Northeastern Ohio University College of Pharmacy, Rootstown, $\mathrm{OH}, 44272$, USA. ${ }^{4}$ The Division of Hematology and Oncology, The Ohio State University, Columbus, $\mathrm{OH}$, 43210, USA. ${ }^{5}$ Division of Cardiovascular Medicine, The Ohio State University, Columbus, OH, 43210, USA. ${ }^{6}$ Department of Medicine, Comprehensive Cancer Center of Case Western Reserve University and University Hospitals of Cleveland, Cleveland, OH, 44106, USA. ${ }^{7}$ Loyola University Chicago Stritch School of Medicine, Chicago, IL, 60660, USA. ${ }^{8}$ Department of Internal Medicine, The Ohio State University, Columbus, $\mathrm{OH}$, 43210, USA

\section{Authors' contributions}

MGP wrote the manuscript, designed and performed experiments. PM, LD, and TK assisted in experiments. ML and AC contributed to data analysis. BRA designed experiments and wrote the manuscript. All authors read and approved the final manuscript.

\section{Competing interests}

The authors declare that they have no competing interests.

Received: 29 January 2009

Accepted: 21 January 2010 Published: 21 January 2010

\section{References}

1. Demetri GD, Griffin JD: Granulocyte colony-stimulating factor and its receptor. Blood 1991, 78:2791-2808.

2. Williams GT, Smith CA, Spooncer E, Dexter TM, Taylor DR: Haemopoietic colony stimulating factors promote cell survival by suppressing apoptosis. Nature 1990, 343:76-79.

3. Begley CG, Metcalf $D$, Nicola NA: Binding characteristics and proliferative action of purified granulocyte colony-stimulating factor (G-CSF) on normal and leukemic human promyelocytes. Exp Hematol 1988, 16:71-79.

4. Avalos BR, Gasson JC, Hedvat C, Quan SG, Baldwin GC, Weisbart RH, Williams RE, Golde DW, DiPersio JF: Human granulocyte colonystimulating factor: biologic activities and receptor characterization on hematopoietic cells and small cell lung cancer cell lines. Blood 1990 75:851-857.

5. Hammond WP, Chatta GS, Andrews RG, Dale DC: Abnormal responsiveness of granulocyte-committed progenitor cells in cyclic neutropenia. Blood 1992, 79:2536-2539.

6. Lieschke GJ, Grail D, Hodgson G, Metcalf D, Stanley E, Cheers C, Fowler KJ Basu S, Zhan YF, Dunn AR: Mice lacking granulocyte colony-stimulating factor have chronic neutropenia, granulocyte and macrophage progenitor cell deficiency, and impaired neutrophil mobilization. Blood 1994, 84:1737-1746.

7. Avalos BR: Molecular analysis of the granulocyte colony-stimulating factor receptor. Blood 1996, 88:761-777.

8. Avalos BR, Broudy VC, Ceselski SK, Druker BJ, Griffin JD, Hammond WP: Abnormal response to granulocyte colony-stimulating factor (G-CSF) in canine cyclic hematopoiesis is not caused by altered G-CSF receptor expression. Blood 1994, 84:789-794
9. Hermans $\mathrm{MH}$, Ward AC, Antonissen C, Karis A, Lowenberg B, Touw IP: Perturbed granulopoiesis in mice with a targeted mutation in the granulocyte colony-stimulating factor receptor gene associated with severe chronic neutropenia. Blood 1998, 92:32-39.

10. Liu F, Wu HY, Wesselschmidt R, Kornaga T, Link DC: Impaired production and increased apoptosis of neutrophils in granulocyte colonystimulating factor receptor-deficient mice. Immunity 1996, 5:491-501.

11. McLemore ML, Poursine-Laurent J, Link DC: Increased granulocyte colonystimulating factor responsiveness but normal resting granulopoiesis in mice carrying a targeted granulocyte colony-stimulating factor receptor mutation derived from a patient with severe congenital neutropenia. $J$ Clin Invest 1998, 102:483-492.

12. Richards MK, Liu F, Iwasaki H, Akashi K, Link DC: Pivotal role of granulocyte colony-stimulating factor in the development of progenitors in the common myeloid pathway. Blood 2003, 102:3562-3568.

13. Semerad CL, Poursine-Laurent J, Liu F, Link DC: A role for G-CSF receptor signaling in the regulation of hematopoietic cell function but not lineage commitment or differentiation. Immunity 1999, 11:153-161.

14. Schmitz S, Franke H, Loeffler M, Wichmann HE, Diehl V: Reduced variance of bone-marrow transit time of granulopoiesis - a possible pathomechanism of human cyclic neutropenia. Cellular Proliferation 1994, 27:655-667.

15. Schmitz S, Franke H, Brusis J, Wichmann HE: Quantification of the cell kinetic effects of G-CSF using a model of human granulopoiesis. Exp Hematol 1993, 21:755-760.

16. Jilma B, Hergovich $N$, Homoncik M, Jilma-Stohlawetz $P$, Kreuzer $C$ Eichler HG, Zellner M, Pugin J: Granulocyte colony-stimulating factor (GCSF) downregulates its receptor (CD114) on neutrophils and induces gelatinase B release in humans. Br J Haematol 2000, 111:314-320.

17. Levesque JP, Takamatsu Y, Nilsson SK, Haylock DN, Simmons PJ: Vascular cell adhesion molecule-1 (CD106) is cleaved by neutrophil proteases in the bone marrow following hematopoietic progenitor cell mobilization by granulocyte colony-stimulating factor. Blood 2001, 98:1289-1297.

18. Levesque JP, Hendy J, Winkler IG, Takamatsu Y, Simmons PJ: Granulocyte colony-stimulating factor induces the release in the bone marrow of proteases that cleave c-KIT receptor (CD117) from the surface of hematopoietic progenitor cells. Exp Hematol 2003, 31:109-117.

19. Valenzuela-Fernandez A, Planchenault T, Baleux F, Staropoli I, Le Barillec K, Leduc D, Delaunay T, Lazarini F, Virelizier JL, Chignard M, Pidard D, Arenzana-Seisdedos F: Leukocyte elastase negatively regulates Stromal cell-derived factor-1 (SDF-1)/CXCR4 binding and functions by aminoterminal processing of SDF-1 and CXCR4. J Biol Chem 2002, 277:15677-15689.

20. El Ouriaghli F, Fujiwara H, Melenhorst JJ, Sconocchia G, Hensel N, Barrett AJ: Neutrophil elastase enzymatically antagonizes the in vitro action of GCSF: implications for the regulation of granulopoiesis. Blood 2003, 101

21. Hunter MG, Druhan LJ, Massullo PR, Avalos BR: Proteolytic cleavage of granulocyte colony-stimulating factor and its receptor by neutrophil elastase induces growth inhibition and decreased cell surface expression of the granulocyte colony-stimulating factor receptor. Am J Hematol 2003, 74.

22. Avalos BR, Hunter MG, Parker JM, Ceselski SK, Druker BJ, Corey SJ, Mehta VB: Point mutations in the conserved box 1 region inactivate the human granulocyte colony-stimulating factor receptor for growth signal transduction and tyrosine phosphorylation of p75c-rel. Blood 1995, 85:3117-3126.

23. Hunter MG, Avalos BR: Deletion of a critical internalization domain in the G-CSFR in acute myelogenous leukemia preceded by severe congenital neutropenia. Blood 1999, 93:440-446.

24. Heldin $\mathrm{CH}$ : Dimerization of cell surface receptors in signal transduction. Cell 1995, 80:213-223

25. Sorkin A, Eriksson A, Heldin CH, Westermark B, Claesson-Welsh L: Pool of ligand-bound platelet-derived growth factor beta-receptors remain activated and tyrosine phosphorylated after internalization. J Cell Physiol 1993, 156:373-382.

26. Strous GJ, van Kerkhof P, Govers R, Ciechanover A, Schwartz AL: The ubiquitin conjugation system is required for ligand-induced endocytosis and degradation of the growth hormone receptor. EMBO J 1996, 15:3806-3812.

27. Vieira AV, Lamaze C, Schmid SL: Control of EGF receptor signaling by clathrin-mediated endocytosis. Science 1996, 274:2086-2089. 
28. Khwaja A, Carver J, Jones HM, Paterson D, Linch DC: Expression and dynamic modulation of the human granulocyte colony-stimulating factor receptor in immature and differentiated myeloid cells. $\mathrm{Br} J$ Haematol 1993, 85:254-259.

29. Dong F, Hoefsloot LH, Schelen AM, Broeders CA, Meijer Y, Veerman AJ, Touw IP, Lowenberg B: Identification of a nonsense mutation in the granulocyte-colony-stimulating factor receptor in severe congenital neutropenia. Proc Natl Acad Sci USA 1994, 91:4480-4484.

30. Dong F, Brynes RK, Tidow N, Welte K, Lowenberg B, Touw IP: Mutations in the gene for the granulocyte colony-stimulating-factor receptor in patients with acute myeloid leukemia preceded by severe congenital neutropenia. N Engl J Med 1995, 333:487-493.

31. Hunter MG, Avalos BR: Granulocyte colony-stimulating factor receptor mutations in severe congenital neutropenia transforming to acute myelogenous leukemia confer resistance to apoptosis and enhance cell survival. Blood 2000, 95:2132-2137.

32. Ward AC, van Aesch YM, Schelen AM, Touw IP: Defective internalization and sustained activation of truncated granulocyte colony-stimulating factor receptor found in severe congenital neutropenia/acute myeloid leukemia. Blood 1999, 93:447-458.

33. Hollenstein U, Homoncik M, Stohlawetz PJ, Marsik C, Sieder A, Eichler HG, Jilma B: Endotoxin down-modulates granulocyte colony-stimulating factor receptor (CD114) on human neutrophils. J Infect Dis 2000, 182:343-346

34. Brignone C, Munoz O, Batoz M, Rouquette-Jazdanian A, Cousin J Proteases produced by activated neutrophils are able to release soluble CD23 fragments endowed with proinflammatory effects. FASEB J 2001, 15:2027-2029

35. Le Barillec K, Si-Tahar M, Balloy V, Chignard M: Proteolysis of monocyte CD14 by human leukocyte elastase inhibits lipopolysaccharide-mediated cell activation. J Clin Invest 1999, 103:1039-1046.

36. Levesque JP, Hendy J, Takamatsu Y, Simmons PJ, Bendall LJ: Disruption of the CXCR4/CXCL12 chemotactic interaction during hematopoietic stem cell mobilization induced by GCSF or cyclophosphamide. J Clin Invest 2003, 111:187-196.

37. Sadallah S, Hess C, Miot S, Spertini O, Lutz H, Schifferli JA: Elastase and metalloproteinase activities regulate soluble complement receptor 1 release. Eur J Immunol 1999, 29:3754-3761.

38. Petit I, Szyper-Kravitz M, Nagler A, Lahav M, Peled A, Habler L, Ponomaryov T, Taichman RS, Arenzana-Seisdedos F, Fujii N, Sandbank J, Zipori D, Lapidot T: G-CSF induces stem cell mobilization by decreasing bone marrow SDF-1 and up-regulating CXCR4. Nat Immunol 2002, 3:687-694.

39. van Os R, van Schie ML, Willemze R, Fibbe WE: Proteolytic enzyme levels are increased during granulocyte colony-stimulating factor-induced hematopoietic stem cell mobilization in human donors but do not predict the number of mobilized stem cells. J Hematother Stem Cell Res 2002, 11:513-521.

40. Belaaouaj A, McCarthy R, Baumann M, Gao Z, Ley TJ, Abraham SN, Shapiro SD: Mice lacking neutrophil elastase reveal impaired host defense against gram negative bacterial sepsis. Nat Med 1998, 4:615-618.

41. Campbell EJ, Campbell MA, Boukedes SS, Owen CA: Quantum proteolysis by neutrophils: implications for pulmonary emphysema in alpha 1antitrypsin deficiency. J Clin Invest 1999, 104:337-344.

42. Liou TG, Campbell EJ: Nonisotropic enzyme-inhibitor interactions: a novel nonoxidative mechanism for quantum proteolysis by human neutrophils. Biochemistry 1995, 34:16171-16177.

43. Renesto P, Chignard M: Enhancement of cathepsin G-induced platelet activation by leukocyte elastase: consequence for the neutrophilmediated platelet activation. Blood 1993, 82:139-144.

44. Samarkos M, Aessopos A, Fragodimitri C, Karagiorga M, Kalotychou V, Voskaridou E, Kavouklis E, Loukopoulos D: Neutrophil elastase in patients with homozygous beta-thalassemia and pseudoxanthoma elasticum-like syndrome. Am J Hematol 2000, 63:63-67.
45. Benson KF, Li FQ, Person RE, Albani D, Duan Z, Wechsler J, Meade-White K, Williams K, Acland GM, Niemeyer G, Lothrop CD, Horwitz M: Mutations associated with neutropenia in dogs and humans disrupt intracellular transport of neutrophil elastase. Nat Genet 2003, 35.

doi:10.1186/1476-9255-7-5

Cite this article as: Piper et al:: Neutrophil elastase downmodulates native G-CSFR expression and granulocyte-macrophage colony formation. Journal of Inflammation 2010 7:5.

\section{Submit your next manuscript to BioMed Central and take full advantage of:}

- Convenient online submission

- Thorough peer review

- No space constraints or color figure charges

- Immediate publication on acceptance

- Inclusion in PubMed, CAS, Scopus and Google Scholar

- Research which is freely available for redistribution

Submit your manuscript at www.biomedcentral.com/submit
C Biomed Central 